\title{
The Protective Effect of Grape Seed Extract on Cardiotoxicity Induced by Doxorubicin Drug in Male Rats
}

\author{
Noorah Saleh Al-Sowayan, Nadia H. Mahmoud \\ Department of Biology, Faculty of Science, Qassim University, Buraydah, Saudi Arabia \\ Email: knaaj1@yahoo.com
}

Received 27 October 2014; revised 25 November 2014; accepted 15 December 2014

Copyright (C) 2014 by authors and Scientific Research Publishing Inc.

This work is licensed under the Creative Commons Attribution International License (CC BY).

http://creativecommons.org/licenses/by/4.0/

\section{(c) (i) Open Access}

\begin{abstract}
Objective: This work was designed to determine the productive effect of grape seed proanthocynadine extract (GSPE) and Vitamin E against Doxorubicin (DOX) induced myocardial toxicity in $\mathbf{5 0}$ male. Wister rates were divided in five groups. The $1^{\text {st }}$ group was untreated and served as a control. The $2^{\text {nd }}$ group was treated with DOX only, the $3^{\text {rd }}$ group was pretreated with GSPE, the $4^{\text {th }}$ group was pretreated with Vitamin E, and the $5^{\text {th }}$ group was pretreated with GSPE and Vitamin E. DOX was administered by single i.p (Intraperitonial) injection of $15 \mathrm{mg} / \mathrm{kg} / \mathrm{body}$ weight to induce cardio toxicity and Vitamin E was administered at a dose of $400 \mathrm{IU} / \mathrm{kg} / \mathrm{bodyweight} /$ day, p.o (per oral) for 10 days prior to DOX administration [1]. GSPE was given at a dose of $150 \mathrm{mg} / \mathrm{kg} / \mathrm{bodyweight} /$ day, p.o (per oral) for 10 days before treatment with DOX. After 2 weeks experimental period, blood samples and heart tissues were taken from all groups. The general observations, mortality, histopathology, biomarker enzymes like Lactate Dehydrogenase (LDH), Creatine Phosphokinase (CPK), Aspartate Aminotransferase (AST), Alanine Aminotransferase (ALT), Antioxidants such as Glutathione (GSH), Superoxide dismutase (SOD), Catalase (CAT) and Malondialdehyde (MDA) were monitored after 2 weeks of the last dose. Results: Administration of DOX caused cardiomyopathy associated with an antioxidant deficiency. Pretreatment with GSPE and Vitamin E significantly (P< 0.01) protected the myocardium from the toxic effects of DOX by reducing the elevated level of biomarkers and diagnostic enzymes like LDH, CPK, AST, and ALT to normal levels. GSPE and Vitamin E increased the GSH, SOD and CAT levels and decreased the MDA levels in cardiac tissue. Conclusion: These results suggest a cardioprotective effect of GSPE and Vitamin E due to its antioxidant properties.
\end{abstract}

\section{Keywords}

Grape Seed Proanthocynadin Extract, Vitamin E, Doxorubicin, Antioxidants, Cardiotoxicity, Oxidative Stress 


\section{Introduction}

The pathogenesis of cardiovascular lesion development is a multifactorial process involving a number of different cell types, covariates, injuries and dysfunction of the vascular endothelium. These are important markers and are likely to participate in the initiation and progression of most forms of heart disease. In addition to chronic dysfunction of endothelial response to patients with established heart disease, there is evidence that "acute insults" can cause measureable dysfunction in vascular response in humans (drug toxicities). Such repeated acute insults may contribute to disease risk in healthy individuals and promote disease progression in established patients [2].

Free radicals have been implicated in over 100 disease conditions in humans, including arthritis, hemorrhagic shocks, atherosclerosis, ischemia, tumor promotion, carcinogenesis and cardiovascular toxicity [3].

The use of chemotherapeutic agents in cancer treatment is often accompanied by side effects due to oxidative stress. Increased lipid peroxidation, reduced antioxidant vitamins, free radical trapping capacity in plasma and a marked reduction of tissue Glutathione (GSH) levels are frequently reported during chemotherapy [4]. The enhanced production of reactive oxygen species (ROS) damages normal tissues and therefore results in toxic side effects of chemotherapeutic agents. In particular, tissue and cells with a high proliferation rate are most affected by the oxidative stress [5]. ROS generated during cancer chemotherapy may also decrease the efficacy of the treatment by interfering with drug induced apoptosis and cell cycle progression, which are optimal effect on cancer cells [6] [7]. Doxorubicin (DOX) is one of the most widely used and successful chemotherapeutic anti-tumour drugs prescribed in hematological malignancies and solid tumors [8]. Its clinical application is limited due to its cumulative dose-related cell toxicity.

Doxorubicin-induced cardiomyopathy and congestive heart failure were reported in the 1970s. Numerous studies have focused on the mechanism of anthracycline cardiotoxicity. Studies have suggested that the mechanism of Doxorubicin-induced cardiotoxicity involve the formation of free oxygen radicals, expression of nitric oxide, damage of myocardial mitochondria and alterations of molecular signaling [9] [10]. Amongst these diverse hypotheses, free oxygen radicals from Adriamycin semiquinones are generally believed to play a major role in the pathogenesis of Doxorubicin-induced heart failure [9]-[11]. The heart is highly susceptible to oxidative stress because of the relatively low expression of antioxidant enzymes, such as catalase and superoxide dismutase [9] [12]. On previous study Ferraro et al. (2000) reported that Doxorubicin initiates apoptosis of both G0 - G1 and cycling peripheral blood lymphocytes and induces massive deletion of mature T and B cells in the spleen, lymph nodes and thymus [13]. Doxorubicin has been shown to be a potent generator of ROS by either an enzymatic pathway or the formation of a Doxorubicin- $\mathrm{Fe}^{3+}$ complex [14]-[16]. These ROSs can then attack membranes or macromolecules and cause lipid peroxidation, which can lead to serious acute and chronic side effects. Acute side effects include myelotoxicity and haematological toxicity, which can cause dysfunction of immune responses, but the major chronic side effect is cardiotoxicity, which leads to critical and life-threatening congestive heart failure. It is clear that Doxorubicin-induced cardiotoxicity is due to an increase in oxidative stress caused by free radical overproduction and a decrease in endogenous antioxidant reserve.

To better understand the theory of free radical involvement in Doxorubicin-induced cardiotoxicity, a number of antioxidant compounds have been screened for ameliorating Doxorubicin-induced histological changes in cardiac myocytes. Antioxidants, such as ascorbic acid and Vitamin E have been shown to exert protective effects from cardiac cell damage [17] [18]. More attention has been paid to the protective effects of natural antioxidants against toxicity induced by chemotherapeutic agents, especially whenever free radical generations are involved.

Recently, several polyphenolic antioxidants derived from grape seeds and skin has been implicated in cell protection [19]. Grape seed proanthocyanidin have been demonstrated to exhibit a broad spectrum of pharmacological, therapeutic and chemo-protective properties. Grape seed proanthocyanidin extract (GSPE) demonstrates significant cytotoxicity towards human breast, lung and gastric adenocarcinoma cells [20]. Epidemiological and experimental studies have revealed that mild to moderate drinking of wine, particularly red wine attenuates not only the kidney and liver diseases, but also the cardiovascular, cerebrovascular and peripheral vascular risks. Although the biochemical basis for such health benefits is not fully understood, this effect has been attributed to the alcohol-free portion containing antioxidants [21]. Vitamin E, a free-radical scavenger in the lipid compartments of cells and serum is known for its beneficial antioxidant effects for a number of chronic diseases including cancer [22]. Increased serum Vitamin E levels have been reported to decrease lipid peroxidation, inhibit protein kinase C, 5-lipoxygen-ase,smooth muscle cell proliferation, platelet aggregation and oxygen burst in neutrophils and the oxygen burst in neutrophils [23] [24]. 
Pre-treatment with Vitamin E supplementation has been proven to show neuroprotective effect in patients treated with cisplatin [25]. It has been reported to prevent several changes in serum enzymes and to protect increase in hematocrit, fall in leukocyte count, hemoglobin level and mean osmotic fragility of erythrocytes [26]. Another study such as meta-analysis is required to investigate whether coinvestigation of vitamin and GSPE attenuates the therapeutic of DOX in cancer patients.

The present study was carried out to examine anti-oxidant potential of GSPE along with Vitamin E on DOX induced cardiotoxicity. Since the free radicals produced during the metabolism of the drug are considered to be responsible for alteration in various cellular enzyme activities, lipid peroxidation, antioxidant and antioxidant enzymes; the effect of antioxidant GSPE together with Vitamin E (which intercepts the toxic free radicals) was investigated in rats.

\section{Material and Methods}

\subsection{Drugs and Chemicals}

Proanthocyanidin (GSPE) and $\alpha$-tocopherol-acetate was purchased from Sigma Chemicals, St Louis, MO, USA. All other chemicals were of analytical grade and solvents were of Qualigen grade, procured from local commercial sources.

\subsection{Animal Model}

Adult male rats of Wister strain weighing $200 \pm 50$ gm were maintained under standard conditions of humidity, temperature $\left(25^{\circ} \mathrm{C} \pm 2^{\circ} \mathrm{C}\right)$ and light $(12 \mathrm{~h}$ light/dark). They were fed standard rat pelleted diet obtained from Lipolin India and offered water ad libitum. Experimental animals were handled according to the institutional legislation, regulated by the Committee for the Purpose of Control and Supervision of Experiments on Animals (CPCSEA).

\subsection{Experimental Design}

Following the acclimatization period, the rats were randomly divided into five equal groups i.e. 10 rats in each group. Group I consisted of rats maintained on commercial rat chow diet throughout the experimental period and served as a control. Group II consisted of rats maintained on a commercial rat chow diet and treated with DOX intraperitoneally at a dose of $15 \mathrm{mg} / \mathrm{kg} /$ bodyweight to induce cardiotoxicity. Group III rats were maintained on a commercial rat chow diet and received GSPE at a dose of $150 \mathrm{mg} / \mathrm{kg} /$ bodyweight/day, p.o (per oral) [27] for 10 days before treatment with DOX. Group IV consisted of rats maintained on a commercial rat chow and treated with Vitamin E at a dose of $400 \mathrm{IU} / \mathrm{kg} /$ bodyweight/day, p.o (per oral) [1] for 10 days prior to DOX administration. Group V consisted of rats maintained on a commercial rat chow with co-treatment with GSPE and Vitamin E for 10 days before injection with DOX.

At the end of experimental period the test animals were sacrificed by cervical decapitation under ether anesthesia and liver was excised immediately and washed with ice-cold saline. A homogenate (10\%) of washed tissue (liver) was prepared in $0.01 \mathrm{M}$ phosphate buffer ( $\mathrm{pH}$ 7.4). The homogenate was centrifuged at 12,000 rpm for $30 \mathrm{~min}$; using high speed refrigerated centrifuge (Remi) at $4^{\circ} \mathrm{C}$. The blood samples collected in plain centrifuge tube were kept in inclined position to allow the complete clotting of blood and then were centrifuged at $2500 \mathrm{rpm}$ for $30 \mathrm{~min}$. The resultant clear supernatant was pipetted out and preserved in small vials in the freezer at $-20^{\circ} \mathrm{C}$ until assay for estimation of the following: 1) Total cholesterol was measured by an enzymatic method [28]; 2) Low density lipoprotein cholesterol (LDL-c) was measured by a chemical method [29]; 3) High density lipoprotein cholesterol (HDL-c) [30]; 4) Triglycerides (TG) [31]; 5) Aspartate Aminotransferase (AST) and 6) Alanine Aminotransferase (ALT) [32]; 7) Lactic Dehydrogenase (LDH) [33]; 8) Gamma Glutamyl Transferase (GGT) [34]; 9) Superoxide Dismutase (SOD) [35]; 10) Catalase (CAT) and 11) Malondialdehyde (MDA) [36] Creatine Phoskinase (CPK) [37], Alkaline Phosphatase (ALP) [38].

Histopathological examination for apoptotic and necrotic cell death in the liver was also performed.

\subsection{Statistical Analysis}

The results were subjected to statistical analysis (SPSS software Package) using One-Way ANOVA, followed 
by Dunnets multiple comparison tests. Values were considered significant at $\mathrm{P}<0.05$.

\section{Results}

Chronic administration of DOX induced cardio toxicity and effect of GSPE and Vitamin E was established by measuring cardiac marker enzymes, endogenous antioxidants and heart tissue histopathology.

We found that intraperitonial administration of DOX had profound effect on heart as assessed by cardiac marker enzymes and histopathology of heart tissue i.e. the mean lipid profile was significantly increased $\mathrm{P}<$ 0.05 except HDL-c levels, which were significantly $(\mathrm{P}<0.05)$ decreased compared to control rats (Table 1$)$. AST, ALT, and GGT levels were significantly $(\mathrm{P}<0.05)$ increased (Table 2), while liver SOD and CAT levels were significantly $(\mathrm{P}<0.05)$ decreased compared to control rats (Table 3$)$. MDA levels were significantly $(\mathrm{P}<$ 0.05) increased compared with those in control rats (Table 4). GSPE administration prior to DOX treatment did not result in any changes in total cholesterol and triglycerides but there was a significant $(P<0.05)$ decrease in LDL-C, while there was a significant $(\mathrm{P}<0.05)$ increase in HDL-c compared to those in DOX treated rats (Table 1), while there was no change in AST, ALT, LDH and GGT levels compared with those in the DOX treated group, liver SOD and CAT level were significantly increased $(\mathrm{P}<0.05)$ compared with those in DOX treated rats (Table 1, Table 2), while there was no change in MDA levels compared with those in the DOX group there were no changes in lipid profiles, except for a significant increase in HDL-c $(P<0.05)$ levels in the Vitamin E treated group compared with the DOX treated group (Table 1, Table 4). Additionally, there were no changes in AST, ALT, and GGT levels in Vitamin E treated group liver SOD, CAT, and MDA levels were significantly increased $(\mathrm{P}<0.05)$ compared with those in DOX treated group (Tables 2-4).

Combined treatment with GSPE and Vitamin E significantly improved $(\mathrm{P}<0.05)$ the lipid profile by decreasing total cholesterol and triglycerides and HDL-c level to normal as compared to DOX treated groups (Table 1).

Liver function was significantly $(\mathrm{P}<0.05)$ decreased, with a significant $(\mathrm{P}<0.05)$ increase in SOD, CAT, and MDA levels compared with those in DOX treated group (Table 3, Table 4).

\section{Histopathological Changes in DOX Treated Rats:}

Figure 1: Shows histopathological alternations in DOX-exposed rats. The DOX administration resulted in severe necrotic changes along with inflammatory cells and marked fragmentation of muscle fibers. The heart showed congestion of myocardial vessels and lack of cross striations in most of the cardiac myocytes (Figure 1(b), Figure 1(c)). Increased cytoplasmic eosinophilia was also seen (Figure 1(d)). Pyknosis of nuclei of cardiac myocytes was occasionally noted (Figure $1(\mathrm{e})$ ).

Table 1. Effects of proanthocyanidin extract or/and Vitamin E on serum lipid profile levels in normal and Doxorubicin in treated rats.

\begin{tabular}{|c|c|c|c|c|c|c|c|c|c|c|c|c|}
\hline \multirow[b]{3}{*}{ Group } & \multicolumn{12}{|c|}{ Parameter } \\
\hline & \multicolumn{3}{|c|}{ Total cholesterol (mg/dl) } & \multicolumn{3}{|c|}{ LDL-c (mg/dl) } & \multicolumn{3}{|c|}{ HDL-c (mg/dl) } & \multicolumn{3}{|c|}{ Triglycerides (mg/dl) } \\
\hline & $\begin{array}{l}\text { Mean } \\
\pm \text { S.E. }\end{array}$ & $\begin{array}{c}\text { (Ta) } \\
\text { significant } \\
\text { test }\end{array}$ & $\begin{array}{c}(\mathrm{Tb}) \\
\text { significant } \\
\text { test }\end{array}$ & $\begin{array}{l}\text { Mean } \\
\pm \text { S.E. }\end{array}$ & $\begin{array}{c}\text { (Ta) } \\
\text { significant } \\
\text { test }\end{array}$ & $\begin{array}{c}(\mathrm{Tb}) \\
\text { significant } \\
\text { test }\end{array}$ & $\begin{array}{l}\text { Mean } \\
\pm \text { S.E. }\end{array}$ & $\begin{array}{l}\text { (Ta) } \\
\text { significant } \\
\text { test }\end{array}$ & $\begin{array}{c}(\mathrm{Tb}) \\
\text { significant } \\
\text { test }\end{array}$ & $\begin{array}{l}\text { Mean } \\
\pm \text { S.E. }\end{array}$ & $\begin{array}{l}(\mathrm{Ta}) \\
\text { significant } \\
\text { test }\end{array}$ & $\begin{array}{c}(\mathrm{Tb}) \\
\text { significant } \\
\text { test }\end{array}$ \\
\hline Control & $\begin{array}{l}70.80 \\
\pm 3.76\end{array}$ & - & $0.000^{*}$ & $\begin{array}{l}33.12 \\
\pm 2.31\end{array}$ & - & $0.000^{*}$ & $\begin{array}{l}25.20 \\
\pm 1.71\end{array}$ & - & $0.024^{*}$ & $\begin{array}{l}62.40 \\
\pm 3.51\end{array}$ & - & $0.013^{*}$ \\
\hline DOX & $\begin{array}{l}108.33 \\
\pm 7.94\end{array}$ & $0.000^{*}$ & - & $\begin{array}{l}58.33 \\
\pm 5.42\end{array}$ & $0.000^{*}$ & - & $\begin{array}{r}30.83 \\
\pm 1.77\end{array}$ & $0.024^{*}$ & - & $\begin{array}{l}84.50 \\
\pm 6.53\end{array}$ & $0.013^{*}$ & - \\
\hline $\begin{array}{l}\text { DOX pretreated } \\
\text { with grape seed } \\
\text { extract (GSPE) }\end{array}$ & $\begin{array}{l}113.28 \\
\pm 2.51\end{array}$ & $0.000^{*}$ & 0.427 & $\begin{array}{r}63.61 \\
\pm 1.41\end{array}$ & $0.000^{*}$ & 0.240 & $\begin{array}{l}33.28 \\
\pm 1.91\end{array}$ & $0.001^{*}$ & 0.266 & $\begin{array}{l}77.00 \\
\pm 4.80\end{array}$ & 0.080 & 0.334 \\
\hline $\begin{array}{l}\text { DOX pretreated } \\
\text { with Vitamin E }\end{array}$ & $\begin{array}{l}104.85 \\
\pm 3.29\end{array}$ & $0.000^{*}$ & 0.576 & $\begin{array}{l}57.62 \\
\pm 3.41\end{array}$ & $0.000^{*}$ & 0.874 & $\begin{array}{l}31.71 \\
\pm 0.74\end{array}$ & $0.008^{*}$ & 0.687 & $\begin{array}{r}77.57 \\
\pm 5.81\end{array}$ & 0.069 & 0.372 \\
\hline $\begin{array}{l}\text { DOX pretreated } \\
\text { with grape seed } \\
\text { extract (GSPE) } \\
\text { combined with } \\
\text { Vitamin E }\end{array}$ & $\begin{array}{l}87.28 \\
\pm 3.04\end{array}$ & $0.017^{*}$ & $0.002^{*}$ & $\begin{array}{l}45.91 \\
\pm 4.56\end{array}$ & $0.010^{*}$ & $0.009^{*}$ & $\begin{array}{l}26.85 \\
\pm 1.35\end{array}$ & 0.473 & 0.077 & $\begin{array}{r}63.00 \\
\pm 5.23\end{array}$ & 0.941 & $0.009^{*}$ \\
\hline
\end{tabular}

The mean difference is significant at the 0.05 level ( ${ }^{*}$ ); (Ta): significant as compared with normal control group. (Tb): significant as compared with DOX group. 
Table 2. Effects of proanthocyanidin extract or/and Vitamin E on serum AST, ALT, CK and ckMB activity in normal and Doxorubicin treated rats.

\begin{tabular}{|c|c|c|c|c|c|c|c|c|c|c|c|c|}
\hline \multirow[b]{3}{*}{ Group } & \multicolumn{12}{|c|}{ Parameter } \\
\hline & \multicolumn{3}{|c|}{ AST (U/L) } & \multicolumn{3}{|c|}{ ALT (U/L) } & \multicolumn{3}{|c|}{ CK (U/L) } & \multicolumn{3}{|c|}{ ckMB (U/L) } \\
\hline & $\begin{array}{l}\text { Mean } \\
\pm \text { S.E. }\end{array}$ & $\begin{array}{c}\text { (Ta) } \\
\text { significant } \\
\text { test }\end{array}$ & $\begin{array}{l}\text { (Tb) } \\
\text { significant } \\
\text { test }\end{array}$ & $\begin{array}{l}\text { Mean } \\
\pm \text { S.E. }\end{array}$ & $\begin{array}{c}\text { (Ta) } \\
\text { significant } \\
\text { test }\end{array}$ & $\begin{array}{c}(\mathrm{Tb}) \\
\text { significant } \\
\text { test }\end{array}$ & $\begin{array}{l}\text { Mean } \\
\pm \text { S.E. }\end{array}$ & $\begin{array}{c}\text { (Ta) } \\
\text { significant } \\
\text { test }\end{array}$ & $\begin{array}{c}(\mathrm{Tb}) \\
\text { significant } \\
\text { test }\end{array}$ & $\begin{array}{l}\text { Mean } \\
\pm \text { S.E. }\end{array}$ & $\begin{array}{c}\text { (Ta) } \\
\text { significant } \\
\text { test }\end{array}$ & $\begin{array}{c}(\mathrm{Tb}) \\
\text { significant } \\
\text { test }\end{array}$ \\
\hline Control & $\begin{array}{r}158.166 \\
\pm 14.031\end{array}$ & - & 0.428 & $\begin{array}{c}71.00 \\
\pm 6.491\end{array}$ & - & $0.020^{*}$ & $\begin{array}{c}466.33 \\
\pm 100.02\end{array}$ & - & 0.295 & $\begin{array}{r}160.33 \\
\pm 35.50\end{array}$ & - & 0.106 \\
\hline DOX & $\begin{array}{c}174.40 \\
\pm 11.075\end{array}$ & 0.428 & - & $\begin{array}{r}108.60 \\
\pm 3.203\end{array}$ & $0.020^{*}$ & - & $\begin{array}{c}568.4 \\
\pm 68.92\end{array}$ & 0.295 & - & $\begin{array}{r}56.40 \\
\pm 6.85\end{array}$ & 0.106 & - \\
\hline $\begin{array}{l}\text { DOX pretreated } \\
\text { with grape seed } \\
\text { extract (GSPE) }\end{array}$ & $\begin{array}{c}202.42 \\
\pm 17.075\end{array}$ & $0.024^{*}$ & 0.162 & $\begin{array}{c}80.71 \\
\pm 12.050\end{array}$ & 0.493 & 0.068 & $\begin{array}{l}481.57 \\
\pm 48.49\end{array}$ & 0.864 & 0.356 & $\begin{array}{l}281.85 \\
\pm 34.59\end{array}$ & $0.043^{*}$ & $0.001^{*}$ \\
\hline $\begin{array}{l}\text { DOX pretreated } \\
\text { with grape seed } \\
\text { extract (GSPE) } \\
\text { combined with } \\
\text { Vitamin E }\end{array}$ & $\begin{array}{r}149.42 \\
\pm 6.931\end{array}$ & 0.641 & 0.211 & $\begin{array}{c}86.00 \\
\pm 14.249\end{array}$ & 0.292 & 0.136 & $\begin{array}{l}312.00 \\
\pm 25.97\end{array}$ & 0.090 & $0.010^{*}$ & $\begin{array}{c}148.57 \\
\pm 32.27\end{array}$ & 0.838 & 0.137 \\
\hline
\end{tabular}

The mean difference is significant at the 0.05 level $\left(^{*}\right)$; (Ta): significant as compared with normal control group. (Tb): significant as compared with DOX group.

Table 3. Effects of proanthocyanidin extract or/and Vitamin E on serum SOD and nitric oxide in normal and Doxorubicin treated rats.

\begin{tabular}{|c|c|c|c|c|c|c|}
\hline \multirow{3}{*}{ Group } & \multicolumn{6}{|c|}{ Parameter } \\
\hline & \multicolumn{3}{|c|}{$\mathrm{SOD}(\mathrm{u} / \mathrm{ml})$} & \multicolumn{3}{|c|}{ Nitric oxide $(\mu \mathrm{mol} / \mathrm{l})$} \\
\hline & Mean \pm S.E. & $\begin{array}{l}\text { (Ta) significant } \\
\text { test }\end{array}$ & $\begin{array}{l}\text { (Tb) significant } \\
\text { test }\end{array}$ & Mean \pm S.E. & $\begin{array}{l}\text { (Ta) significant } \\
\text { test }\end{array}$ & $\begin{array}{l}\text { (Tb) significant } \\
\text { test }\end{array}$ \\
\hline Control & $13.13 \pm 0.908$ & - & $0.000^{*}$ & $20.58 \pm 0.849$ & - & 0.090 \\
\hline DOX & $4.74 \pm 0.423$ & $0.000^{*}$ & - & $11.50 \pm 1.696$ & $0.002^{*}$ & - \\
\hline $\begin{array}{l}\text { DOX pretreated with grape } \\
\text { seed extract (GSPE) }\end{array}$ & $10.33 \pm 1.137$ & $0.017^{*}$ & $0.000^{*}$ & $12.55 \pm 1.875$ & $0.005^{*}$ & $0.000^{*}$ \\
\hline DOX pretreated with Vitamin E & $13.25 \pm 0.495$ & 0.920 & $0.000^{*}$ & $25.34 \pm 2.75$ & 0.090 & $0.000^{*}$ \\
\hline $\begin{array}{l}\text { DOX pretreated with grape seed extract } \\
\text { (GSPE) combined with Vitamin E }\end{array}$ & $16.54 \pm 0.484$ & $0.005^{*}$ & $0.000^{*}$ & $19.54 \pm 0.825$ & 0.693 & $0.027^{*}$ \\
\hline
\end{tabular}

The mean difference is significant at the 0.05 level ( $\left.{ }^{*}\right)$; (Ta): significant as compared with normal control group. (Tb): significant as compared with DOX group.

Table 4. Effects of GSPE and Vitamin E on lipid peroxidation and antioxidant enzyme activity in DOX-treated rats.

$\begin{array}{ccc}\text { Group (s) } & \text { LPO (nmol of MDA/mg protein) } & \text { CAT ( } \mu \text { moles of } \mathrm{H}_{2} \mathrm{O}_{2} \text { consumed/mg protein) } \\ \text { Control } & 1.09 \pm 0.069 & 6.39 \pm 0.331 \\ \text { DOX } & 4.06 \pm 0.119 & 3.78 \pm 0.220 \\ \text { DOX pretreated with grape seed extract (GSPE) } & 2.28 \pm 0.187 & 5.47 \pm 0.208 \\ \text { DOX pretreated with Vitamin E } & 2.50 \pm 0.289 & \\ \text { DOX pretreated with grape seed extract (GSPE) } \\ \text { combined with Vitamin E }\end{array}$

Results are the mean \pm SEM; P $<0.05$ considered significant. Comparisons are made between control, DOX, GSPE + DOX and Vitamin E + DOX. 


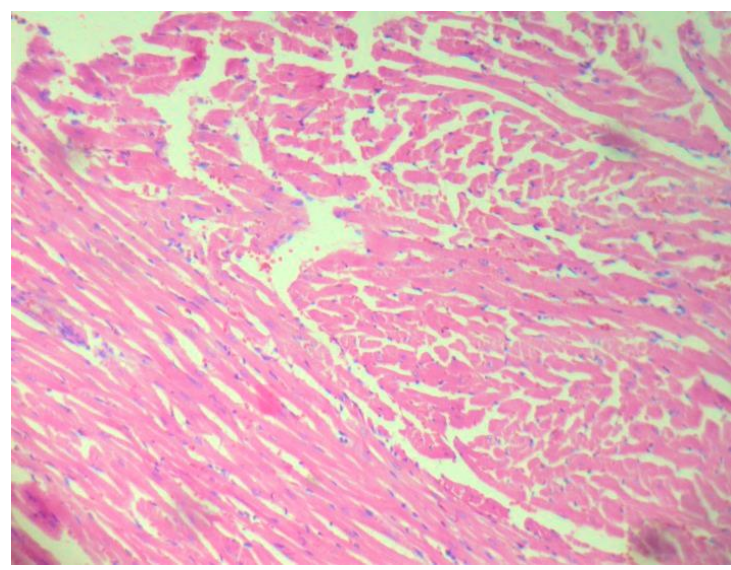

(a)

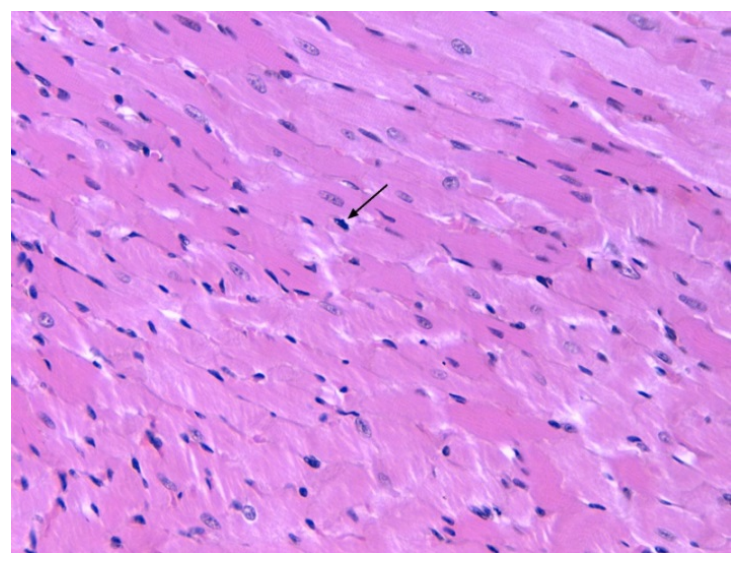

(c)

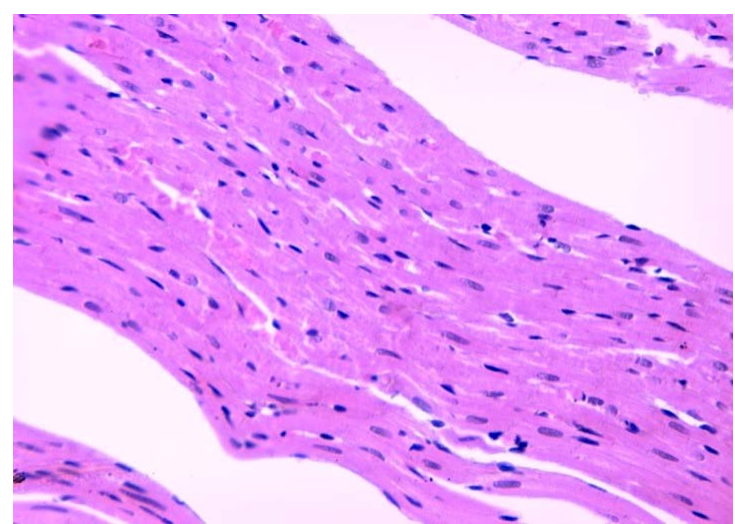

(e)

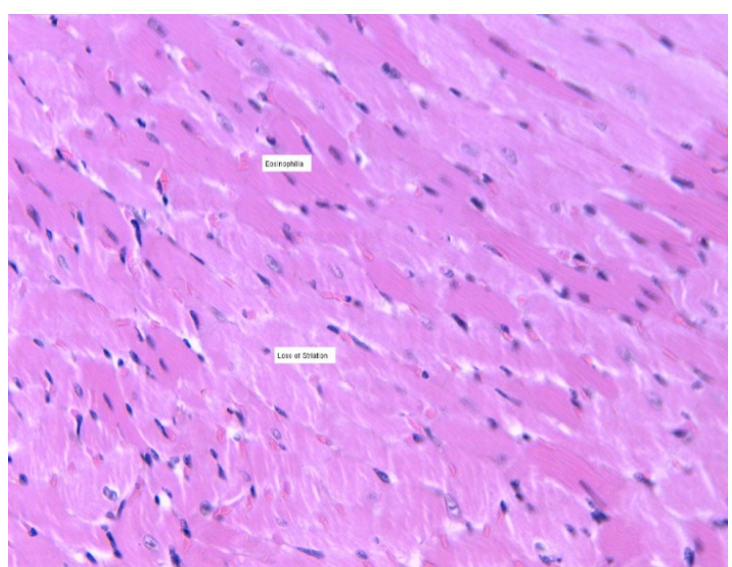

(b)

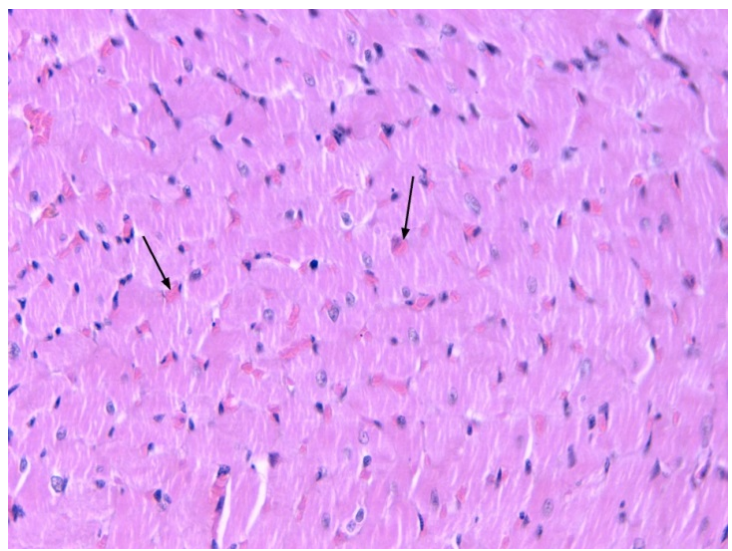

(d)

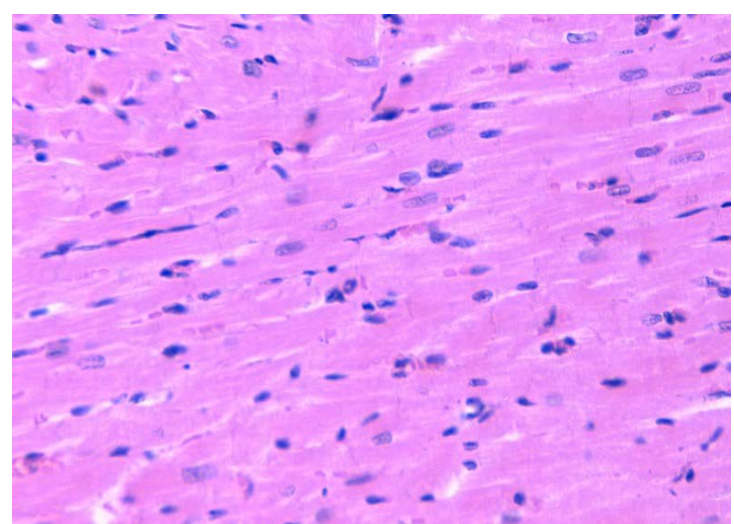

(f)

Figure 1. Photomicrograph of a section in a cardiac muscle (H \& E staining, magnification $\times 10)$. (a) Normal control; (b) DOX (15 mg/kg/b.w, i.p); (c) DOX (15 mg/kg/b.w, i.p); (d) GSPE + DOX; (e) Vitamin E + DOX; (f) Vitamin E + GSPE + DOX.

\section{Group 1}

Figure 1(a): Represent myocardium of control rats showing normal architecture of the muscle fibers with abundant wavy cytoplasm and small nuclei.

\section{Group 2}

Figure 1(b): Section of myocardium shows lack of cross striations and that most of the myocytes in the upper half of this micrograph show increased sarcoplasmic eosinophilia. 
Figure 1(c): Section of myocardium shows the difference in eosinophilic staining of the sarcoplasm. Most myocytes have normal pale granular central nuclei, many have peripheral pyknotic flattened nuclei; Few (arrow) have pyknotic central nuclei.

\section{Group 3}

Figure 1(d): Section of myocardium shows congestion of blood capillaries and absence of cross striations.

\section{Group 4}

Section of myocardium shows mild changes in cardiac myocyte staining intensity. Feeble cross striations and intercalated discs were evident. Most of myocytic nuclei appeared pale, oval and granular; few myocytes had condensed flattened nuclei (Figure 1(e)).

Figure 1(e): Feeble cross striations and intercalated discs (arrows) are seen.

\section{Groups 5}

Section of myocardium shows no apparent changes in cardiac myocyte staining intensity. Feeble cross striations and intercalated discs were evident. Most of myocytic nuclei appeared pale, oval and granular; few myocytes had condensed flattened nuclei (Figure 1(f)).

Figure 1(f): Feeble cross striations and intercalated discs (arrows) are seen.

\section{Discussion}

In agreement with previous studies using acute and chronic treatment with Doxorubicin [39] [40], our results show that this anthracycline significantly increase ROS production in cardiac mitochondria, cytosol and sarcoplasmic reticulum [41]. This explains the pathological picture of anthracycline cardioctoxicity characterized by disruption of heart mitochondrial and sarcoplasminc reticulum membranes [42] by drug induced free radical formation in specific myocardial compartments [41]. The free radical hypothesis has been supported by the finding that free radical scavengers attenuate anthracycline-induced myocardial morphofuncianal alternations [43].

Several studies have revealed that polyphenolic antioxidant derived from grape seed extract shows significant pharmacological therapeutic and chemo-protective properties [19].

Antioxidants are compounds that protect cells against the damaging effects of ROS, such as superoxide, hydrogen peroxide, singlet oxygen, peroxyl radicals, hydroxyl radicals and peroxynitrite [44]. Some ROS, such as superoxide and hydrogen peroxide, are normally produced in cells as by-products of biochemical reactions or as signaling molecules [44] [45]. When ROS-generating reactions are activated excessively, pathological quantities of ROS are released to create an imbalance between antioxidants and ROS. Oxidative stress has been linked to cardiovascular disease, diabetes, pulmonary disease, cancer, and other degenerative diseases [44]. Herbal antioxidants may protect against these diseases by contributing to the total antioxidant defense system of the human body [46] [47]. The efficacy of herbal antioxidants has been suggested in several studies. For example many epidemiological studies have shown that intake of flavonoids, a group of herbal antioxidants, are inversely related to mortality from coronary heart disease and to the incidence of heart attack [48].

Currently, a considerable amount of research focuses on the ROS-mediated pathophysiology of different diseases. These illness cause significant patient morbidity and escalate healthcare costs [45]. Several medications for the treatment of these diseases are believed to act through an antioxidant mechanism. Thus, one can envision the scope and impact of the use of antioxidant herbs. They could mediate health benefits by partially eliminating pathological amounts of ROS [49]. If their value in promoting antioxidant tissue defense is established using contemporary methods, antioxidant herbs may also have a potential role in preventing and treating diseases [50] [51].

Antioxidant botanicals may reduce ROS activity either directly or indirectly. The active constituents found in several antioxidant herbs are known to react directly with ROS by scavenging and reducing ROS activity [52]-[54]. The active constituents found in several antioxidant herbs can affect cellular functions, including gene expression and enzymes that promote ROS dynamics [55] [56]. The ability of antioxidant herbs to affect various pathological processes mediated by ROS depends on their ability to access the sites or sub-cellular compartments (i.e., mitochondria, cytosolic organelles, nucleus) of biochemical activity.

There are many species of grapevines, but most wine grapes are from Vitis vinifera L. (Vitaceae). Grape seed proanthocyanidins extract (GSPE) which possesses a broad spectrum of pharmacological, medicinal and therapeutic properties [48] [57] [58], is a popular herbal supplement with patients suffering from cardiovascular dis- 
ease in the US. Grape seed proanthocyanidins are polyphenolic bioflavonoids, present in lignified portions of grape clusters, especially in the seeds. Tannins are natural polyphenol. On the basis of structural characteristics, tannins are divided into four major groups: gallotannins, ellagitannins, complex tannins, and condensed tannins. Polyphenols from grape seeds, which are oligomeric and polymeric proanthocyanidins that belong to condensed tannins, are the main antioxidant components in grape seed extracts.

Polyphenolic compounds are ubiquitous in nature. They are categorized according to chemical structure as flavonoids (such as flavanols, flavonols, flavones, flavanones, isoflavones, and anthocyanidins). More than 4000 flavonoids have been identified, many of which are found in fruits, vegetables, tea, coffee, beer, wine, and fruit drinks. Over the past several years, increasing evidence has strongly suggested that moderate consumption of wine or alcohol has been associated with a reduced incidence of mortality and morbidity from coronary heart disease [59].

The capacity of flavonoids to act as antioxidants depends upon their molecular structure. The position of hydroxyl groups and other features in the chemical structure of flavonoids are important for their antioxidant and free radical scavenging activities. In GSPE, the main polyphenol components are (+)-catechin (C), (-)-epicatechin (EC), (-)-epicatechin gallate (ECG) and proanthocyanidin dimer B2 (EC-EC). Polyphenols are powerful antioxidants. Phenolic antioxidants (PPH) inhibit lipid peroxidation by a rapid donation of hydrogen atom to the peroxyl radical (ROO) resulting in formation of alkyl (aryl) hydroperoxide (ROOH), as illustrated in the following reaction: $\mathrm{ROO}+\mathrm{PPH} \rightarrow \mathrm{ROOH}+\mathrm{PP}$. The polyphenol phenoxyl radical (PP) produced can be stabilized by further donation of a hydrogen atom and formation of quinones [45], or by reacting with another radical, including another phenoxyl radical, to generate new components [60], thereby interrupting the initiation of a new chain reaction.

The antioxidant components in GSPE are catechins, similar to those in green tea extract (see below). However, their structure differs from the polyphenols of green tea. In GSPE, polyphenols are composed of C, EC and gallic acid (GA) unit; the composition units of polyphenols in green tea extract are mostly (-)-epigallocatechin (EGC) and GA.

The antioxidant properties of GSPE were previously summarized [3]. The GSPE attenuated $\mathrm{H}_{2} \mathrm{O}_{2}$-induced oxidant stress in cardiomyocytes. Antioxidant action is associated with an increase in cardiomyocyte survival and contractile function. The extract had cardioprotective effects against reperfusion-induced injury by reducing or removing, directly or indirectly, free radicals in the myocardium of an isolated rat heart that was reperfused after ischemia.

Postprandial hyperlipemia is a well-defined risk factor for atherosclerosis [61]. The supplementation of a meal with GSPE minimizes the postprandial oxidative stress by decreasing the oxidants and increasing the antioxidant levels in plasma. As a consequence, it enhances the resistance to oxidative modification of LDL in human subjects. GSPE is superior to conventional antioxidants such as Vitamin E and Vitamin C. In one study, TPA-induced lipid peroxidation in mice brain and liver was significantly attenuated with GSPE pretreatment compared to that with conventional antioxidants [62].

Direct scavenging activity of GSPE appears to be an important component of its antioxidant protection. GSPE successfully scavenged superoxide, hydroxyl and peroxyl radicals. When compared its scavenging ability for superoxides and hydroxyl radicals, GSPE scavenged more superoxides than hydroxyl radicals [63]. When GSPE was combined with Vitamin E, all radicals, such as superoxides, hydroxyl, and methyl were scavenged [63]. This result suggests herbs with varied scavenging potentials can be combined to increase the radical scavenging activities.

Other mechanisms of antioxidant effects may be involved, such as nitric oxide-releasing action, which could help to attenuate oxidant formation. GSPE reduced the apoptotic effect of chemotherapeutic agents, thus reducing their toxicity [64]. Since apoptotic genes are regulated via ROS signaling, these results may suggest modulation of ROS signaling.

Proanthocyanidin has been reported to have a broad spectrum of pharmacological and medicinal properties against oxidative stress. GSPE has significantly better free radical scavenging ability than Vitamin E and shows significant cytotoxicity towards gastric adenocarcinoma cells, while enhancing the growth of normal cells [3].

In the previous study [65] pre-exposure of GSPE to DOX-induced cardiotoxicity provided almost complete protection of serum chemistry changes i.e. ALT and CPK-MPand DNA damage.

In an attempt to ameliorate the chemotherapy associated cytotoxicity, we investigated the effect of GSPE on cardio toxicity. We found that GSPE administration prior to DOX treatment did not result in any changes in total 
cholesterol and triglycerides but there was a significant $(\mathrm{P}<0.05)$ decrease in LDL-c while there was a significant $(\mathrm{P}<0.05)$ increase in HDL-c compared to DOX-treated rats and there was no change in AST, ALT, LDH and GGT levels compared with those in the DOX-treated group. SOD and CAT levels were also increased while MDA levels did not change compared to DOX-treated group. In the present study, oral administration of GPSE improved SOD and CAT levels. A previous study showed that GPSE administration reduced the levels of lipid peroxides and enhanced the antioxidant defense against reactive oxygen species produced under DOX treatment, thereby protecting liver cells [66].

Electrocardiographic and bio chemical evidence for the cardio protective effect of Vitamin $\mathrm{E}$ in DOX induced acute cardiotoxicity in rats was studied by Puri et al., 2005 and showed that Vitamin E treatment helped to decrease the levels of CPK-MP and LDH that were increased due to myocardial damage caused by DOX. Increased Vitamin E level in serum have been reported to decease lipid peroxidation and decease protein kinase C. 5-lipooxygenaze smooth muscle cell proliferation, platelet aggregation and oxygen burst in neutrophil [23] [24].

With regard to Vitamin E treatment we found that there were no changes in the lipid profile except for a significant increase in HDL-c levels compared with the DOX-treated group. There were also no changes in AST, ALT and GGT levels compared with those in the DOX-treated group. Liver SOD, CAT and MDA levels were significantly increased $(\mathrm{P}<0.05)$ compared with those in DOX-treated group.

In present study it is also noted that GSPE alone is more effective than Vitamin E to restore LPO levels, which is also in accordance with previous study [3].

Combined treatment with proanthocyanidin and Vitamin E significantly improved $(\mathrm{P}<0.05)$ the lipid profile by decreasing total cholesterol, triglycerides and returning HDL-c levels to normal. Additionally, serum levels were significantly $(\mathrm{P}<0.05)$ decreased compared with that in the DOX-treated group, with a significant $(\mathrm{P}<$ 0.05) increase in SOD, CAT and MDA levels compared with those in the DOX-treated group. It has been found that co-administration of $\alpha$-tocopherol and DOX significantly minimizes lipid peroxide formation by DOX [67] which is in accordance to our present study. Histopathological observations are also in the correlation with the biochemical parameters. Moreover, in future it is needed to investigate whether co-administration of GSPE and Vitamin E attenuates the therapeutic effects of DOX in cancer patients and for that another meta-analysis is required. These findings indicate the protective effects of GSPE and Vitamin E in combinations during DOX induced myocardial infarction in rats. Further investigations are needed on the mechanisms of action of GSPE and Vitamin E as they affect salient cellular and molecular pathways involved in the major diseases. Data obtained from future studies will have the potential for translation into practical benefits for human health.

\section{Conclusion}

The present results suggest that GSPE along with Vitamin E prevents the DOX induced myocardial toxicity by boosting the endogenous antioxidant activity.

\section{Acknowledgements}

We express our sincere gratitude and thanks to Deanship of Scientific Research in Qassim University for funding this research.

\section{References}

[1] Folts, J.D. (2002) Potential Health Benefits from the Flavonoids in Grape Products on Vascular Disease. Advances in Experimental Medicine and Biology, 505, 95-111. http://dx.doi.org/10.1007/978-1-4757-5235-9_9

[2] Chaves, A.A., Joshi, M.S., Coyle, C.M., Brady, J.E., Dech, S.J., Schanbacher, B.L., Baliga, R., Basuray, A. and Bauer, J.A. (2009) Vasoprotective Endothelial Effects of a Standardized Grape Product in Humans. Vascular Pharmacology, 50, 20-26. http://dx.doi.org/10.1016/j.vph.2008.08.004

[3] Bagchi, D., Bagchi, M., Stohs, S.J., Das, D.K., Ray, S.D., Kuszynski, C.A., Joshi, S.S. and Pruess, H.G. (2000) Free Radicals and Grape Seed Proanthocyanidin Extract: Importance in Human Health and Disease Prevention. Toxicology, 148, 187-197. http://dx.doi.org/10.1016/S0300-483X(00)00210-9

[4] Goncalves, T.L., Benvegnu, D.M., Bonfanti, G., Frediani, A.V. and Rocha J.B. (2009) Delta-ALA-D Activity Is a Reliable Marker for Oxidative Stress in Bone Marrow Transplant Patients. BMC Cancer, 9, 138. http://dx.doi.org/10.1186/1471-2407-9-138

[5] Conklin, K.A. (2000) Dietary Antioxidants during Cancer Chemotherapy: Impact on Chemotherapeutic Effectiveness 
and Development of Side Effects. Nutrition and Cancer, 37, 1-18. http://dx.doi.org/10.1207/S15327914NC3701_1

[6] Conklin, K.A. (2004) Chemotherapy-Associated Oxidative Stress: Impact on Chemotherapeutic Effectiveness. Integrative Cancer Therapies, 3, 294-300. http://dx.doi.org/10.1177/1534735404270335

[7] Wessner, B., Strasser, E.M., Koitz, N., Schmuckenschlager, C., Unger-Manhart, N. and Roth, E. (2007) Green Tea Polyphenol Administration Partly Ameliorates Chemotherapy Induced Side Effects in the Small Intestine of Mice. Journal of Nutrition, 137, 634-64.

[8] Li, W., Xu, B., Xu, J. and Wu, X.L. (2009) Procyanidins Produce Significant Attenuation of Doxorubicin-Induced Cardiotoxicity via Suppression of Oxidative Stress. Basic Clinical Pharmacology Toxicology, 104, 192-197. http://dx.doi.org/10.1111/j.1742-7843.2008.00358.x

[9] Minotti, G., Menna, P., Salvatorelli, E., Cairo, G. and Gianni, L. (2004) Anthracyclines: Molecular Advances and Pharmacologic Developments in Antitumor Activity and Cardiotoxicity. Pharmacological Reviews, 56, 185-229. http://dx.doi.org/10.1124/pr.56.2.6

[10] Takemura, G. and Fujiwara, H. (2007) Doxorubicin-Induced Cardiomyopathy from the Cardiotoxic Mechanisms to Management. Progress in Cardiovascular Diseases, 49, 330-352. http://dx.doi.org/10.1016/j.pcad.2006.10.002

[11] Davies, K.J. and Doroshow, J.H. (1986) Redox Cycling of Anthracyclines by Cardiac Mitochondria. I. Anthracycline Radical Formation by NADH Dehydrogenase. Journal of Biological Chemistry, 261, 3060-3067.

[12] Doroshow, J.H. (1983) Anthracycline Antibiotic-Stimulated Superoxide, Hydrogen Peroxide and Hydroxyl Radical Production by NADH Dehydrogenase. Cancer Research, 43, 4543-4551.

[13] Ferraro, C., Quemeneur, L., Prigent, A.F., Taverne, C., Revillard, J.P. and Bonnefoy-Berard, N. (2000) Anthracyclines Trigger Apoptosis of both G0 - G1 and Cycling Peripheral Blood Lymphocytes and Induce Massive Deletion of Mature T and B Cells. Cancer Research, 60, 1901-1907.

[14] Goodman, J. and Hochstein, P. (1977) Generation of Free Radicals and Lipid Peroxidation by Redox Cycling of Adriamycin and Daunomycin. Biochemical and Biophysical Research Communications, 77, 797-803. http://dx.doi.org/10.1016/S0006-291X(77)80048-X

[15] Nakano, H., Ogita, K., Gutteridge, J.C. and Nakano, M. (1984) Inhibition by the Protein Ceruloplasmin of Lipid Peroxidation Stimulated by an $\mathrm{Fe}^{3+}$-ADP-Adriamycin Complex. FEBS Letters, 166, 232-236.

[16] Zweier, J.L. (1984) Reduction of $\mathrm{O}_{2}$ by Iron-Adriamycin. Journal of Biological Chemistry, 259, 6056-6058.

[17] Sonneveld, P. (1978) Effect of Alpha-Tocopherol on the Cardiotoxicity of Adriamycin in the Rat. Cancer Treatment Reports, 62, 1033-1036.

[18] Villani, F., Galimberti, M., Monti, E., Piccinini, F., Lanza, E., Rozza, A., et al. (1990) Effect of Glutathione and NAcetylcysteine on in Vitro and in Vivo Cardiac Toxicity of Doxorubicin. Free Radical Research, 11, 145-115. http://dx.doi.org/10.3109/10715769009109677

[19] Cui, J., Cordis, G.A., Tosaki, A., Maulik, N. and Das, D.K. (2002) Reduction of Myocardial Ischemia Reperfusion Injury with Regular Consumption of Grapes. Annals of the New York Academy of Sciences, 957, 302-307. http://dx.doi.org/10.1111/j.1749-6632.2002.tb02930.x

[20] Bagchi, D., Ray, S.D., Patel, D. and Bagchi, M. (2001) Protection against Drug- and Chemical-Induced Multiorgan Toxicity by a Novel IH636 Grape Seed Proanthocyanidin Extract. Drugs under Experimental and Clinical Research, 27, 3-15.

[21] Bagchi, D., Ray, S.D., Bagchi, M., Preuss, H.G. and Stohs, S.J. (2002) Mechanistic Pathways of Antioxidant Cytoprotection by a Novel IH636 Grape Seed Proanthocyanidin Extract. Indian Journal of Experimental Biology, 40, 717-726.

[22] Kline, K., Yu, W. and Sanders, B.G. (2004) Vitamin E and Breast Cancer. Journal of Nutrition, 134, 3458S-3462S.

[23] Brigelius-Flohe, R., Kelly, F.J., Salonen, J.T., Neuzil, J., Zingg, J.M. and Azzi, A. (2002) The European Perspective on Vitamin E: Current Knowledge and Future Research. American Journal of Clinical Nutrition, 76, 703-716.

[24] Peralta, E.A., Viegas, M.L., Louis, S., Engle, D.L. and Dunnington, G.L. (2006) Effect of Vitamin E on TamoxifenTreated Breast Cancer Cells. Surgery, 140, 607-615. http://dx.doi.org/10.1016/j.surg.2006.07.007

[25] Pace, A., Savarese, A., Picardo, M., Maresca, V., Pacetti, U., Del Monte, G., Biroccio, A., Leonetti, C., Jandolo, B., Cognetti, F. and Bove, L. (2003) Neuroprotective Effect of Vitamin E Supplementation in Patients Treated with Cisplatin Chemotherapy. Journal of Clinical Oncology, 21, 927-931. http://dx.doi.org/10.1200/JCO.2003.05.139

[26] Sultana, N., Begum, N., Begum, S., Ferdousi, S. and Ali, T. (2006) Effects of Vitamin E Supplementation on Some Aspects of Hematological Variables in Patients of Hemolytic Anemia with Glucose 6 Phosphate Dehydrogenase (G6PD) Deficiency. Bangladesh Journal of Physiology and Pharmacology, 22, 12-17.

[27] Pataki, T., Bak, I., Kovacs, P., Bagchi, D., Das, D.K. and Tosaki, A. (2002) Grape Seed Pro-Anthocyanidins Improved Cardiac Recovery during Reperfusion after Ischemia in Isolated Rat Hearts. American Journal of Clinical Nutrition, 75, 894-899. 
[28] Deeg, R. and Ziegenhorn, J. (1983) Kinetic Enzymic Method for Automated Determination of Total Cholesterol in Serum. Clinical Chemistry, 29, 1798-1802.

[29] Okada, M., Matsui, H., Ito, Y., Fujiwara, A. and Inano, K. (1998) Low-Density Lipoprotein Cholesterol Can Be Chemically Measured: A New Superior Method. Journal of Laboratory and Clinical Medicine, 132, 195-201. http://dx.doi.org/10.1016/S0022-2143(98)90168-8

[30] Durrington, P.N. and Paul Miller, J. (1982) High-Density Lipoprotein Cholesterol: Methods and Clinical Significance. Critical Reviews in Clinical Laboratory Sciences, 18, 31-78. http://dx.doi.org/10.3109/10408368209082589

[31] Howdieshell, T.R., Bhalla, N., DiPiro, J.T., Kuske, T. and Baisden, R. (1995) Effects of Free Glycerol Contained in Intravenous Fat Emulsion on Plasma Triglyceride Determination. JPEN Journal of Parenteral and Enteral Nutrition, 19, 125-126. http://dx.doi.org/10.1177/0148607195019002125

[32] Smith, A.F. and Taylor, R.H. (1972) Comparison of Two-Point (AutoAnalyzer II) with Kinetic Methods for Transaminase Assay. Journal of Clinical Pathology, 26, 42-47. http://dx.doi.org/10.1136/jcp.26.1.42

[33] Menon, M.P., Anderson, G. and Namblar, G.K. (1983) Determination of Human Serum Lactate Dehydrogenase Isoenzymes by Anion Exchange Chromatography. Analytical Chemistry, 55, 1385-1390. http://dx.doi.org/10.1021/ac00259a044

[34] Gjerde, H. and Mørland, J. (1985) Determination of Gamma Glutamyltransferase in Completely Haemolysed Blood Samples. Scandinavian Journal of Clinical \& Laboratory Investigation, 45, 661-664. http://dx.doi.org/10.3109/00365518509155275

[35] Nandi, A. and Chatterjee, I.B. (1988) Assay of Superoxide Dismutase Activity in Animal Tissues. Journal of Biosciences, 13, 305-315. http://dx.doi.org/10.1007/BF02712155

[36] Lukaszewicz-Hussain, A. and Moniuszko-Jakoniuk, J. (2004) Liver Catalase, Glutathione Peroxidase and Reductase Activity, Reduced Glutathione and Hydrogen Peroxide Levels in Acute Intoxication with Chlorfenvinphos, an Organophosphate Insecticide. Polish Journal of Environmental Studies, 13, 303-309.

[37] Allison, G.W., Perla, R.J., Belliveau, P.P. and Angelis, S.M. (2009) Elevated Creatine Phosphokinase Levels Associated with Linezolid Therapy. American Journal of Health-System Pharmacy, 66, 1097-1100. http://dx.doi.org/10.2146/ajhp080228

[38] Park, W., Kim, B.S., Lee, J.E., Huh, J.K., Kim, B.J., Sung, K.C., Kang, J.H., Lee, M.H., Park, J.R., Rhee, E.J., Oh, K.W., Lee, W.Y., Park, C.Y., Park, S.W. and Kim, S.W. (2009) Serum Phosphate Levels and the Risk of Cardiovascular Disease and Metabolic Syndrome: A Double-Edged Sword. Diabetes Research and Clinical Practice, 83, 119-125. http://dx.doi.org/10.1016/j.diabres.2008.08.018

[39] Lenaz, G., Bertoli, E., Curatola, G., Mazzanti, L. and Bigi, A. (1976) Lipid Protein Interactions in Mitochondria: Spin and Fluorescence Probe Studies on the Effect of n-Alkanols on Phospholipid Vesicles and Mitochondrial Membranes. Archives of Biochemistry and Biophysics, 172, 278-288. http://dx.doi.org/10.1016/0003-9861(76)90077-1

[40] Jensen, R.A., Acton, E.M. and Peters, J.H. (1984) Doxorubicin Cardiotoxicity in the Rat: Comparison of Electrocardiogram, Transmembrane Potential, and Structural Effects. Journal of Cardiovascular Pharmacology, 6, 186-200. http://dx.doi.org/10.1097/00005344-198401000-00028

[41] Droshow, J.H. (1983) Effect of Anthracycline Antibiotics on Oxygen Radical Formation in Rat Heart. Cancer Research, 43, 460-472.

[42] Ferrans, V.J. (1978) Overview of Cardiac Pathology in Relation to Anthracycline Cardiotoxicity. Cancer Treatment Reports, 62, 955-961.

[43] Olson, R.D., Boerth, R.C., Gerber, J.G. and Nies, A.S. (1981) Mechanism of Adriamycin Cardiotoxicity: Evidence for Oxidative Stress. Life Sciences, 29, 1393-1401. http://dx.doi.org/10.1016/0024-3205(81)90001-1

[44] Stohs, S.J. (1995) The Role of Free Radicals in Toxicity and Disease. Journal of Basic and Clinical Physiology and Pharmacology, 6, 205-228. http://dx.doi.org/10.1515/JBCPP.1995.6.3-4.205

[45] Cadenas, E. and Packer, L. (2002) Handbook of Antioxidants. 2nd Edition, Marcel Dekker, Inc., New York.

[46] Liu, S.Q., Yu, J.P., Chen, H.L., Luo, H.S., Chen, S.M. and Yu, H.G. (2006) Therapeutic Effects and Molecular Mechanisms of Ginkgo Biloba Extract on Liver Fibrosis in Rats. American Journal of Chinese Medicine, 34, 99-114. http://dx.doi.org/10.1142/S0192415X06003679

[47] Ichikawa, H., Wang, L. and Konishi, T. (2006) Prevention of Cerebral Oxidative Injury by Post-Ischemic Intravenous Administration of Shengmai San. American Journal of Chinese Medicine, 34, 591-600. http://dx.doi.org/10.1142/S0192415X06004120

[48] Chang, W.T., Shao, Z.H., VandenHoek, T.L., McEntee, E., Mehendale, S.R., Li, J., Becker, L.B. and Yuan, C.S. (2006) Cardioprotective Effects of Grape Seed Proanthocyanidins, Baicalin and Wogonin: Comparison between Acute and Chronic Treatments. American Journal of Chinese Medicine, 34, 363-365.

[49] Lee, C.Y., Peng, W.H., Cheng, H.Y., Chen, F.N., Lai, M.T. and Chiu, T.H. (2006) Hepatoprotective Effect of Phyllan- 
thus in Taiwan on Acute Liver Damage Induced by Carbon Tetrachloride. American Journal of Chinese Medicine, 34, 471-482. http://dx.doi.org/10.1142/S0192415X06004004

[50] Chung, S.Y., Cheng, F.C., Lee, M.S., Lin, J.Y., Lin, M.C. and Wang, M.F. (2006) Ginkgo biloba Leaf Extract (EGb761) Combined with Neuroprotective Agents Reduces the Infarct Volumes of Gerbil Ischemic Brain. American Journal of Chinese Medicine, 34, 803-817. http://dx.doi.org/10.1142/S0192415X06004302

[51] Yang, J.H., Tsai, S.Y., Han, C.M., Shih, C.C. and Mau, J.L. (2006) Antioxidant Properties of Glossogyne tenuifolia. American Journal of Chinese Medicine, 34, 707-720. http://dx.doi.org/10.1142/S0192415X06004223

[52] Choi, J., Conrad, C.C., Malakowsky, C.A., Talent, J.M., Yuan, C.S. and Gracy, R.W. (2002) Flavones from Scutellaria baicalensis Georgi Attenuate Apoptosis and Protein Oxidation in Neuronal Cell Lines. Biochimica et Biophysica Acta, 1571, 201-210. http://dx.doi.org/10.1016/S0304-4165(02)00217-9

[53] Hamada, H., Hiramatsu, M., Edamatsu, R. and Mori, A. (1993) Free Radical Scavenging Action of Baicalein. Archives of Biochemistry and Biophysics, 306, 261-266. http://dx.doi.org/10.1006/abbi.1993.1509

[54] Stangl, V., Lorenz, M. and Stangl, K. (2006) The Role of Tea and Tea Flavonoids in Cardiovascular Health. Molecular Nutrition \& Food Research, 50, 218-228. http://dx.doi.org/10.1002/mnfr.200500118

[55] Dalton, T.P., Shertzer, H.G. and Puga, A. (1999) Regulation of Gene Expression by Reactive Oxygen. Annual Review of Pharmacology and Toxicology, 39, 67-101. http://dx.doi.org/10.1146/annurev.pharmtox.39.1.67

[56] Park, C., So, H.S., Kim, S.J., Youn, M.J., Moon, B.S., Shin, S.H., Lee, I., Moon, S.K. and Park, R. (2006) Samul Extract Protects against the $\mathrm{H}_{2} \mathrm{O}_{2}$-Induced Apoptosis of H9c2 Cardiomyoblasts via Activation of Extracellular Regulated Kinases (Erk) 1/2. American Journal of Chinese Medicine, 34, 695-706. http://dx.doi.org/10.1142/S0192415X06004211

[57] Ray, S., Bagchi, D., Lim, P.M., Bagchi, M., Gross, S.M., Kothari, S.C., Preuss, H.G. and Stohs, S.J. (2001) Acute and Long-Term Safety Evaluation of a Novel IH636 Grape Seed Proanthocyanidin Extract. Research Communications in Molecular Pathology and Pharmacology, 109, 165-197.

[58] Wang, C.Z., Fishbein, A., Aung, H.H., Mehendale, S.R., Chang, W.T., Xie, J.T., Li, J. and Yuan, C.S. (2005) Polyphenol Contents in Grape-Seed Extracts Correlate with Antipica Effects in Cisplatin-Treated Rats. Journal of Alternative and Complementary Medicine, 11, 1059-1065. http://dx.doi.org/10.1089/acm.2005.11.1059

[59] Rimm, E.B., Giovannucci, E.L., Willett, W.C., Colditz, G.A., Ascherio, A., Rosner, B. and Stampfer, M.J. (1991) Prospective Study of Alcohol Consumption and Risk of Coronary Disease in Men. Lancet, 338, 464-468. http://dx.doi.org/10.1016/0140-6736(91)90542-W

[60] Hosny, M. and Rosazza, J.P. (2002) Novel Oxidations of (+)-Catechin by Horseradish Peroxidase and Laccase. Journal of Agricultural and Food Chemistry, 50, 5539-5545. http://dx.doi.org/10.1021/jf020503j

[61] Yang, H.L., Hseu, Y.C., Chen, J.Y., Yech, Y.J., Lu, F.J., Wang, H.H., Lin, P.S. and Wang, B.C. (2006) Antrodia camphorata in Submerged Culture Protects Low Density Lipoproteins against Oxidative Modification. American Journal of Chinese Medicine, 34, 217-231. http://dx.doi.org/10.1142/S0192415X06003783

[62] Bagchi, D., Garg, A., Krohn, R.L., Bagchi, M., Bagchi, D.J., Balmoori, J. and Stohs, S.J. (1998) Protective Effects of Grape Seed Proanthocyanidins and Selected Antioxidants against TPA-Induced Hepatic and Brain Lipid Peroxidation and DNA Fragmentation, and Peritoneal Macrophage Activetion in Mice. General Pharmacology, 30, 771-776. http://dx.doi.org/10.1016/S0306-3623(97)00332-7

[63] Yamaguchi, F., Yoshimura, Y., Nakazawa, H. and Ariga, T. (1999) Free Radical Scavenging Activity of Grape Seed Extract and Antioxidants by Electron Spin Resonance Spectrometry in an $\mathrm{H}_{2} \mathrm{O}_{2} / \mathrm{NaOH} / \mathrm{DMSO}$ System. Journal of Agricultural and Food Chemistry, 47, 2544-2548. http://dx.doi.org/10.1021/jf9806762

[64] Joshi, S.S., Kuszynski, C.A., Benner, E.J., Bagchi, M. and Bagchi, D. (1999) Amelioration of the Cytotoxic Effects of Chemotherapeutic Agents by Grape Seed Proanthocyanidin Extract. Antioxidants \& Redox Signaling, 1, 563-570. http://dx.doi.org/10.1089/ars.1999.1.4-563

[65] Ray, S.D., Patel, D., Wong, V. and Bagchi, D. (2000) In Vivo Protection of DNA Damage Associated Apoptotic and Necrotic Cell Deaths during Acetaminophen-Induced Nephrotoxicity, Amiodarone-Induced Lung Toxicity and Doxorubicin-Induced Cardiotoxicity by a Novel IH636 Grape Seed Proanthocyanidin Extract. Research Communications in Molecular Pathology and Pharmacology, 107, 137-166.

[66] Chis, I.C., Ungureanu, M.I., Marton, A., Simedrea, R., Muresan, A., Postescu, I.D. and Decea, N. (2009) Antioxidant Effects of a Grape Seed Extract in a Rat Model of Diabetes Mellitus. Diabetes \& Vascular Disease Research, 6, 200-204.

[67] Geetha, A., Marar, T. and Devi, C.S. (1991) Effect of Alpha-Tocopherol on Doxorubicin-Induced Changes in Rat Liver and Heart Microsomes. Indian Journal of Experimental Biology, 29, 782-785. 
Scientific Research Publishing (SCIRP) is one of the largest Open Access journal publishers. It is currently publishing more than 200 open access, online, peer-reviewed journals covering a wide range of academic disciplines. SCIRP serves the worldwide academic communities and contributes to the progress and application of science with its publication.

Other selected journals from SCIRP are listed as below. Submit your manuscript to us via either submit@scirp.org or Online Submission Portal.
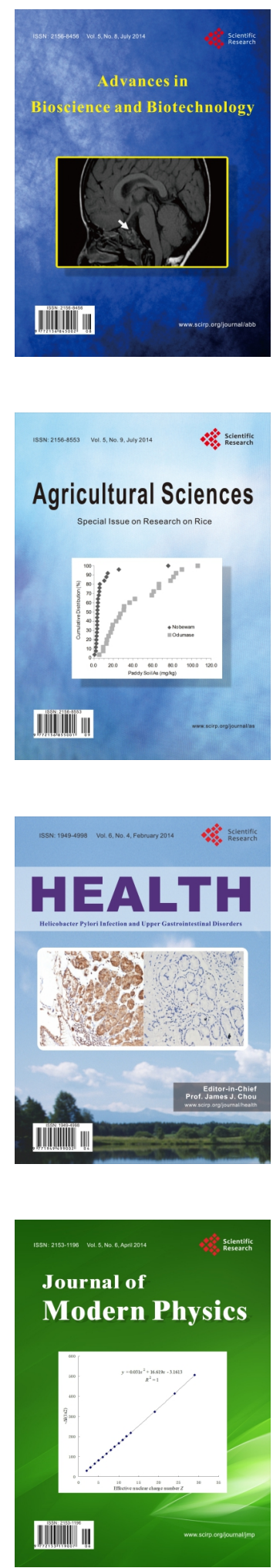
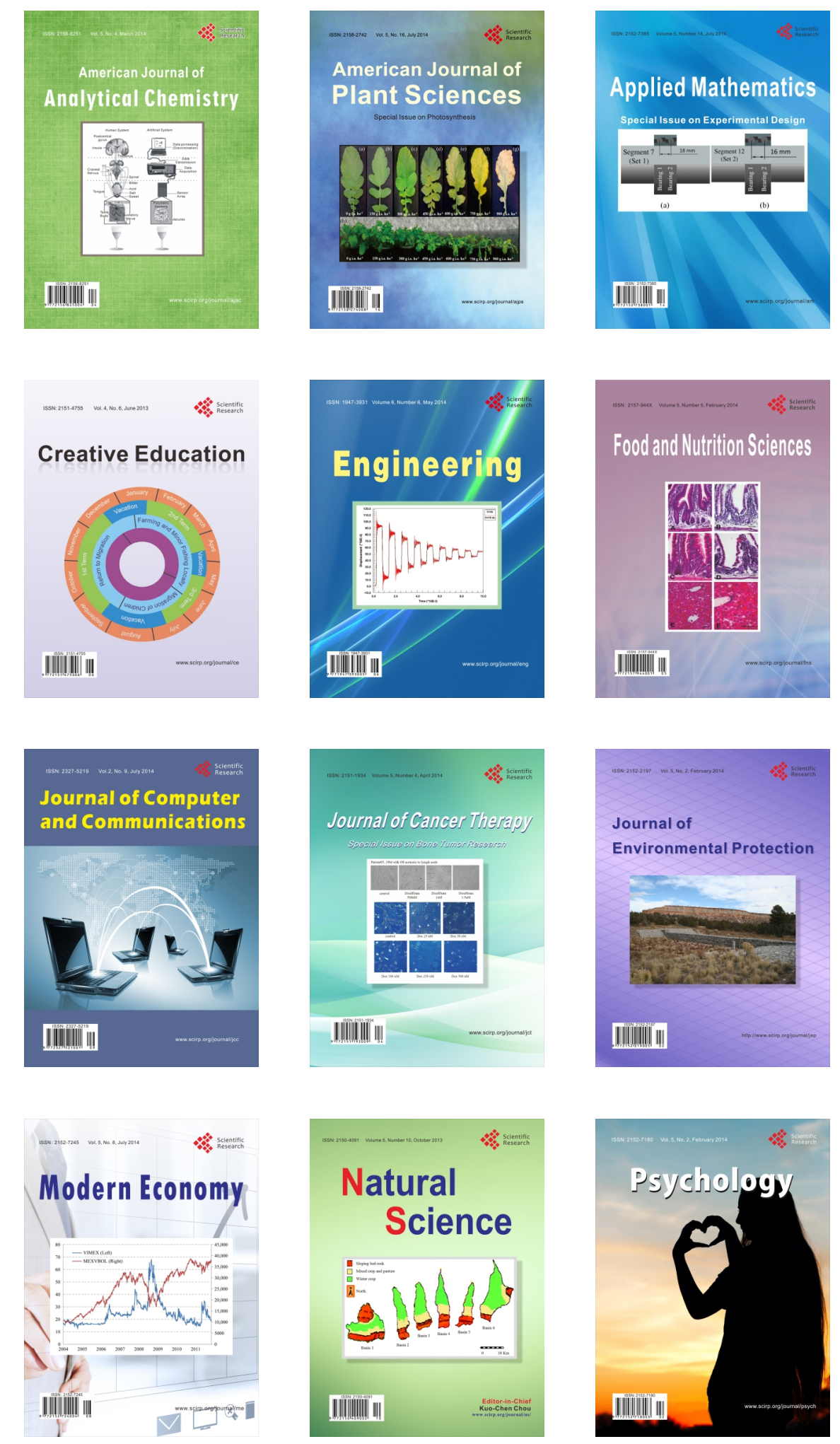